\title{
'Demasiados Académicos' para o ‘Mundo Real'? Doutorados e suas Perspectivas de Carreira no Sector Empresarial
}

\author{
Carlos Cabral-Cardoso
}

\begin{abstract}
RESUMO
Este artigo reporta resultados parciais de um estudo sobre a integração de doutorados em organizações do sector empresarial. O estudo foi realizado em Portugal com uma grande amostra de doutorandos e recém-doutorados, utilizando um inquérito postal, complementado com um conjunto de entrevistas em profundidade. Procura compreender-se a atracção e receptividade a uma carreira nas empresas, a partir das atitudes em relação à ciência enquanto prática de trabalho e enquanto profissão, das expectativas e preferências por actividades e ambientes de trabalho, e da exposição aos valores académicos durante a pós-graduação. $\mathrm{O}$ estudo conclui que a relutância a esse tipo de integração resulta da forma como o indivíduo se posiciona perante os mundos empresarial e académico e das dificuldades derivadas da sobrequalificação percebida, e em alguns casos, experenciada.
\end{abstract}

Palavras-chaves: cientistas; valores académicos e empresariais; cultura académica e cultura profissional; orientação de carreira; escolha de emprego.

\begin{abstract}
This paper addresses the integration of scientists and technologists in industry and reports some of the findings of a major study conducted in Portugal. A survey of a large sample of doctoral students and newly graduated Ph.D.s was conducted and completed with in-depth interviews of a smaller sample of respondents. The paper aims to identify career prospects and assess the extent to which doctors are receptive to a job in industry. It is based on the assumption that such attraction depends on the individuals' attitudes towards science as a profession and towards different academic and business activities and on their exposure to academic values and work practices. It was also found that Ph.D.s perceive themselves as being overqualified for current jobs available in the Portuguese industry.
\end{abstract}

Key words: scientists; academic values and business values; organizational culture and professional culture; career orientation; job choice. 


\section{INTRODUÇÃO}

O esforço português em actividades de investigação e desenvolvimento (I\&D) tem sido tradicionalmente reduzido em termos europeus, sendo a diferença ainda mais evidente quando a comparação é feita com base na I\&D industrial (Gago, 1990; Caraça, 1993). É geralmente aceite que a I\&D realizada na indústria é insuficiente para fazer frente às necessidades decorrentes do novo contexto concorrencial derivado dos processos de globalização e de integração europeia, o que, aliado à deficiente qualificação dos recursos humanos, limita as possibilidades de adopção, nas empresas portuguesas, de estratégias que privilegiem a inovação e o desenvolvimento de conhecimento e de tecnologia. Para ultrapassar estas dificuldades, as instituições financiadoras de formação avançada de recursos humanos têm vindo a adoptar políticas de incremento da oferta de mãode-obra altamente qualificada em diversas áreas das ciências e das tecnologias, com taxas de crescimento médio anual de doutorados de cerca de 10\% (Seixas, 1998), o valor mais elevado no contexto europeu (OCT, 1999).

Todavia, mesmo quando constatam a necessidade de recursos humanos com qualificações ao nível da pós-graduação, as empresas não disfarçam certa desconfiança, aliás muitas vezes fundamentada, em relação a indivíduos com este nível de qualificação, percebidos nos meios empresariais como demasiado académicos. Tradicionalmente absorvidos pelas universidades e, em menor escala, pelos institutos de investigação e laboratórios estatais de I\&D, os detentores de grau de mestre e de doutor sentem particulares dificuldades de integração na economia real, dificuldades agravadas pela longa convivência com a cultura académica que desenvolve, entre os pós-graduados, uma forte identificação com os valores e os interesses profissionais da comunidade científica em detrimento dos valores do mundo dos negócios. Este artigo refere alguns desenvolvimentos de um projecto de investigação que tem sido conduzido desde 1996, sobre o problema da integração de pós-graduados em organizações de tipo empresarial.

A multiplicidade de questões envolvidas na integração de doutorados nas organizações do sector empresarial privado requer a condução de um estudo que aborde o problema na dupla perspectiva dos indivíduos e das organizações. Ao nível das organizações, importa compreender em que medida a integração de indivíduos com elevada qualificação académica pode contribuir para o reforço da posição competitiva, e avaliar o que as organizações empresariais podem fazer para atrair e reter estes quadros, facilitando o seu processo de socialização e ajustamento à cultura empresarial e que políticas concretas podem permitir às 
empresas retirar todos os benefícios da integração destes recursos humanos qualificados. Ao nível do indivíduo, procuram-se identificar padrões de comportamento, atitudes, expectativas e preferências manifestadas em relação à actividade científica e aos possíveis desenvolvimentos profissionais e, deste modo, avaliar a sua receptividade à perspectiva de prossecução de uma carreira em ambiente empresarial. Estes comportamentos podem ser explicados por disposições, valores e crenças sobre o papel da ciência e do cientista, pressupondo-se que as atitudes em relação à profisssão e à ciência são sobretudo influenciadas pelo nível de adesão e de identificação com os valores académicos adquiridos durante a longa exposição a valores e práticas de trabalho universitários a que os estudantes são sujeitos nos seus estudos de graduação e, sobretudo, de pós-graduação. $\mathrm{O}$ ajustamento entre os valores profissionais dos indivíduos e os valores organizacionais percebidos pode afectar decisivamente a atracção exercida por certos tipos de organização, em detrimento de outros. O exposto permite pressupor que a compreensão do relacionamento entre os indivíduos e as organizações não se compadece com abordagens fragmentadas que conduzem a análises parcelares e reducionistas do problema.

Embora integrado em pesquisa de âmbito mais vasto, conduzida em níveis individual, organizacional e interaccional, este artigo incide apenas sobre alguns dos aspectos mais pertinentes, no nível dos indivíduos. Neste sentido, pretende contribuir para compreender o que determina a apetência dos quadros com elevada qualificação académica por uma carreira na indústria, que motivações e expectativas estão associadas a essa atracção, e como compatibilizam os valores adquiridos durante a sua prolongada formação académica com os que esperam encontrar no ambiente empresarial. Para este estudo, são relevantes as contribuições da literatura em diversos domínios, nomeadamente a que aborda a atracção por diferentes ocupações, a que estuda as orientações vocacionais e as identidades profissionais, a que estuda o ajustamento entre o indivíduo e a organização e a que explora os contrastes entre os valores e culturas das organizações de tipo académico e de tipo empresarial. São particularmente relevantes as contribuições da literatura sobre a gestão de cientistas, um domínio que teve algum desenvolvimento a partir dos anos sessenta.

\section{A Atracção dos Cientistas por Diferentes Organizações e Actividades}

A revisão da literatura permitiu confirmar a premissa segundo a qual indivíduos com diferentes valores, atitudes, orientações e preferências são atraídos por organizações com características e natureza diferentes (Bretz, Ash e Dreher, 
1989; Chatman, 1991; Schneider, Goldstein e Smith, 1995). Existe evidência empírica mostrando que os indivíduos são atraídos por organizações cujos valores são percebidos como congruentes com os seus valores individuais (O'Reilly, Chatman e Caldwell, 1991; Judge e Bretz, 1992; Posner, 1992; Meglino e Ravlin, 1998), tendendo a escolher organizações cujas características são percebidas como mais favoráveis para a satisfação das suas necessidades e mais ao encontro das suas preferências (Bretz, Ash e Dreher, 1989; Turban e Keon, 1993; Cable e Judge, 1994). Embora a atracção e escolha da organização esteja mais bem estudada do que a escolha da actividade profissional (Lancaster et al., 1994), existe alguma evidência empírica segundo a qual indivíduos com traços semelhantes tendem a escolher ocupações do mesmo tipo (Holland, 1992). Diversos estudos têm sido levados a cabo com o objectivo de identificar diferenças, ao nível da personalidade, entre cientistas e engenheiros e entre estes e os indivíduos ligados a outras ocupações (Rushton, Murray e Paunonen, 1987; Feist, 1994). Por outro lado, as diferenças entre cientistas provenientes das diversas áreas disciplinares podem contribuir para explicar a maior ou menor dificuldade de adaptação ao desempenho de uma actividade no sector empresarial privado. Scott e Sedlacek (1975), por exemplo, concluíram serem os cientistas mais introspectivos, flexíveis e sensíveis que os engenheiros, enquanto Feist (1994) aponta para a maior complexidade integrativa de químicos e físicos, em comparação com biólogos.

Em termos de escolha de uma organização do tipo empresarial para prosseguir a sua actividade profissional, alguns estudos apontam para a preferência, por parte dos doutorandos, pelas empresas que conduzem I\&D com padrões científicos percebidos como elevados, bem como pelas empresas de maior dimensão (Jones, 1992). Embora alguma literatura atribua a relutância em trabalhar no meio empresarial ao pouco incentivo dado por esta à publicação de artigos científicos por parte dos seus colaboradores, Jones $(1992,1996)$ concluiu que, embora considerada importante, a falta de oportunidade de publicar não seria suficiente para dissuadir os jovens cientistas de trabalhar para um empresa que considerem como um bom empregador. Noutro estudo, McMillan e Deeds (1998) confirmam que a qualidade das equipas de investigação, as condições de trabalho e o salário constituem factores com um peso consideravelmente maior na decisão de doutorandos de escolher um empregador, do que o apoio que a empresa possa dar à publicação científica. O que os pós-graduados consideram um bom empregador parece estar mais dependente de critérios de índole científica do que laboral. Para além dos aspectos atrás referidos, a natureza do trabalho tem sido considerada de primordial importância na atracção e motivação de cientistas que preferem trabalhos estimulantes e que representem um desafio (Miller, 1986). A literatura mostra ainda que os cientistas mais insatisfeitos são os que se consideram subutilizados pela sua organização (Cotgrove e Box, 1970). 
Em suma, os estudos conduzidos noutros contextos indicam que os doutorados valorizam, em primeiro lugar, a excelência científica do trabalho realizado pela empresa como critério de escolha de um empregador, o que sugere que as empresas devem salientar o seu empenhamento nas actividades científicas, se quiserem atrair bons cientistas para as suas equipas.

\section{Valores e Culturas Académicas e Empresariais}

A universidade e a indústria são tradicionalmente descritas como desempenhando diferentes papéis sociais, culturais e económicos, conducentes ao desenvolvimento de valores e culturas distintas. Estas diferenças traduzem-se, para os indivíduos que nelas desenvolvem a sua actividade profissional, em práticas de trabalho, motivações e objectivos distintos, sendo conhecidas as dificuldades de comunicação e de relacionamento, derivadas da falta de compreensão da natureza distinta desses papéis. Assim, à cultura académica das universidades estão associados valores como a produção desinteressada e a difusão de conhecimento, a liberdade académica e a autonomia científica, a colegialidade, a avaliação dos pares, a importância da publicação, um tipo de organização estruturada em bases disciplinares, e um horizonte temporal mais longo. A cultura académica valoriza a independência e é orientada para o reconhecimento pelos pares, o que constitui mesmo o factor fundamental da organização e avaliação do desempenho individual. Nesta cultura, a aquisição de novos conhecimentos é mais importante do que os ganhos financeiros potencialmente obtidos com eles. O horizonte de planeamento no meio académico aproxima-se do longo prazo e as práticas de gestão valorizam o consenso e a segurança no emprego, embora esta última se tenha vindo a diluir progressivamente nas universidades europeias. Destes valores resultam a predominância do trabalho individual sobre o trabalho de equipa, da contribuição para o conhecimento sobre a aplicação produtiva do conhecimento e do empenhamento na ciência sobre o empenhamento organizacional.

Por seu lado, nas organizações orientadas para o negócio, aqui designadas simplesmente por empresas, os resultados financeiros e a posição no mercado constituem as preocupações centrais, em torno das quais são definidas as políticas, nomeadamente as políticas de reconhecimento e compensação de recursos humanos. A hierarquia impera nos processos de decisão e não existe, por via de regra, segurança no emprego. O horizonte temporal da gestão é consideravelmente mais curto do que no meio académico. As actividades desenvolvidas por todos os colaboradores, cientistas e engenheiros incluídos, devem, em última 
análise, traduzir-se na comercialização de produtos ou serviços, o que sublinha a importância da unidade de esforços e do empenhamento na organização. Ou seja, a cultura empresarial não atribui valor particular ao conhecimento em si, se este não for traduzível em bens ou serviços negociáveis no mercado.

Para além das diferenças quanto às configurações estruturais, objectivos, horizontes temporais e práticas de trabalho, encontram-se ainda estratégias de recrutamento e sistemas de reconhecimento e compensação diferenciados. Na universidade, a avaliação de desempenho e o reconhecimento são sobretudo efectuados pelos pares da comunidade científica, valorizando-se a disseminação de resultados através do processo de publicação. A reputação individual e a liberdade de escolha dos temas e métodos de investigação constituem outros dois vectores fundamentais da actividade e da cultura académicas. Na indústria, a actividade de I\&D é conduzida essencialmente tendo em vista a resolução de problemas concretos, sendo o sucesso desta actividade medido, em última análise, através dos resultados económicos e comerciais que derivam dessa actividade. Ao invés das autonomias estratégica e operacional (Pelz e Andrews, 1976; Debackere, Clarysse e Rappa, 1996) adquiridas com a progressão na carreira universitária, a oportunidade de progressão para posições executivas e de gestão constitui um dos processos tradicionais de avaliação do sucesso de uma carreira na indústria.

O difícil relacionamento entre universidades e empresas resulta não apenas dos diferentes papéis desempenhados, mas também do grande desconhecimento mútuo. A literatura mostra que os pós-graduados provenientes das áreas das ciências e das tecnologias em geral, e os doutorados em particular, têm um conhecimento muito limitado do mundo empresarial. Durante o período em que desenvolvem o seu projecto de investigação na universidade, os jovens doutorandos têm pouco acesso a informação sobre as empresas, já que os docentes e investigadores universitários têm normalmente poucos contactos com a economia real e olham para um emprego na indústria como "a saída possível para quem não consegue ficar na universidade" (Jones, 1992). As atitudes negativas relativamente à indústria, que são comuns no meio universitário, reflectem as percepções académicas da empresa, sendo vulgarmente aceite a ideia de que, na empresa, um doutorado executa trabalho rotineiro e é tratado como um empregado e não como um cientista. Para além disso, é comum acreditar-se que, trabalhando na indústria, o doutorado será forçado a orientar o seu trabalho no sentido de obter os resultados que interessem comercialmente à empresa, em lugar de o orientar para a obtenção de resultados que sejam interessantes cientificamente. Esta situação traduz uma diferença clara em termos de valores e, consequentemente, de cultura organizacional. A literatura mostra que quando estas duas culturas se encontram, se segue um processo em que cada uma das partes procura 
que a outra adopte o seu sistema de valores, o que frequentemente leva a situações de conflito (Dubinskas, 1985; Samson e Gurdon, 1993).

O modo como cientistas, engenheiros e gestores interpretam o mundo ou se comunicam e se relacionam entre si tem pouco em comum. As suas perspectivas profissionais e referenciais éticos são também diferentes. Quando integrados em empresas, cientistas e engenheiros criam identidades próprias, vestem-se de forma diferente, decoram o espaço envolvente de modo diverso, têm diferentes estilos de trabalho e diferentes modos de organizar o seu quotidiano, diferentes horizontes temporais e diferentes perspectivas sobre as suas carreiras (Dubinskas, 1985; Kunda, 1992). Por vezes, a única coisa que parece existir em comum é falarem a mesma língua (Samson e Gurdon, 1993). O maior contraste ocorre entre cientistas e gestores e resulta, em grande parte, da diferente educação que estes grupos tiveram. Ao contrário dos gestores, os cientistas doutorados viveram a sua investigação de forma relativamente isolada durante pelo menos três anos a tempo completo, que se segue a um já longo período de estudo de matérias absorventes que normalmente não incluem qualquer componente de ciências sociais e humanas. Esta educação contribui para que desenvolvam uma atitude passiva e reflexiva e métodos de trabalho de grande rigor analítico, que os faz sentirem-se desajustados em ambientes que valorizam a acção e a intervenção e em que as decisões têm de ser tomadas rapidamente e com informação incompleta (Dubinskas, 1985). Por seu lado, são conhecidas as diferenças entre os perfis dos que seguem uma carreira nas ciências e os que seguem uma carreira nas engenharias (Kerr, Von Glinow e Schriesheim, 1977; Allen, 1988), argumentando alguns autores que aquela última se encontra mais próxima das carreiras de gestão do que das carreiras científicas (Shapira e Griffith, 1990). Enquanto os cientistas preferem esforçar-se por conseguir o reconhecimento dos pares, os engenheiros valorizam mais o sucesso económico e o estatuto e tendem a ver a sua profissão como uma fase transitória para um cargo de gestão de topo (Allen, 1988).

Embora alguns autores argumentem que os valores dos cientistas e engenheiros reflectem, antes de mais, a sua própria personalidade (Jackson, 1987), a exposição aos valores e práticas de trabalho académicos desempenha também um papel fundamental na identificação do cientista com os valores académicos (Kerr, Von Glinow e Schriesheim, 1977). Expostos aos valores da cultura académica durante mais tempo, os doutorados continuam a valorizar mais os aspectos relacionados com a aquisição de conhecimento e mantêm as expectativas de contribuição para a ciência na sua área disciplinar. Quando integrados na indústria, mantêm a sua preferência pelo trabalho de investigação e manifestam maior interesse pelo sucesso das suas iniciativas científicas do que pela sua promoção na empresa, ao contrário dos graduados, que valorizam mais o seu salário e a sua promoção na empresa. Os doutorados tendem ainda a manter laços estreitos com 
o mundo académico, o que pode isolá-los do resto da empresa, se esta não tomar as medidas necessárias à transposição do fosso entre os lados técnico e comercial da sua actividade (Allen e Katz, 1986, 1992). Em suma, indivíduos com diferentes níveis de formação e com formação realizada em diferentes áreas tendem a apresentar atitudes e valores distintos, que se traduzem em diferentes comportamentos e expectativas quanto ao seu relacionamento com as organizações potencialmente empregadoras, o que pode contribuir para explicar a maior ou menor facilidade de ajustamento ao contexto profissional das empresas.

\section{Identidades e Orientaçóes de Carreira de Doutorados}

A orientação de carreira influencia as escolhas de carreira e as decisões de mudança de actividade e de empregador, condiciona o modo como o indivíduo vê o seu futuro e o que pretende da sua vida profissional e não-profissional e como percepciona a sua experiência de trabalho, verificando-se existir uma relação estreita entre os valores individuais e as respectivas orientações (Schein, 1971, 1975). Existindo ajustamento entre as expectativas e aspirações de carreira do indivíduo e a actividade desempenhada, são mais elevados os níveis de satisfação e de empenhamento organizacional e mais reduzidas as intenções de sair (Igbarria, Greenhaus e Parasuraman, 1991).

Em termos de orientação de carreira, a literatura tem sugerido diversas tipologias que apontam fundamentalmente para duas orientações distintas. Embora a designação possa variar de autor para autor, no essencial, as tipologias propostas sugerem uma orientação profissional ou científica, normalmente associada a uma maior propensão para a actividade científica e uma orientação organizacional ou burocrática, normalmente associada a uma maior propensão para a actividade de gestão. Alguns autores enfatizam a importância da socialização profissional na orientação de carreira. Miller e Wager (1971), por exemplo, verificaram que a maior duração da formação, até ao nível de doutoramento, estava associada a uma maior orientação profissional, revelando os indivíduos que haviam prosseguido a sua formação até ao nível de mestrado, uma maior orientação burocrática. Também a área científica se verificou estar relacionada com a orientação, sendo as ciências naturais mais associadas à orientação profissional e as tecnologias mais associadas à orientação burocrática.

Para Kornhauser (1962), a orientação profissional encontra-se em indivíduos que valorizam fontes de recompensa mais directamente relacionadas com as suas necessidades profissionais, como a oportunidade de contribuir para o conhecimento científico, a obtenção do respeito dos pares e a possibilidade de se 
associarem a outros profissionais de reputada competência. Miller e Wager (1971) confirmaram empiricamente que a orientação profissional está associada à maior importância atribuída à autonomia estratégica, e à possibilidade de desenvolver actividade científica que constitua uma contribuição para o conhecimento, seja reconhecida pela comunidade científica e possa conduzir a publicações, sem restrições derivadas da preservação dos interesses da empresa. Aryee e Leong (1991), por sua vez, verificaram que estes indivíduos valorizam a contribuição para o conhecimento, o desenvolvimento da sua reputação e a publicação de resultados, preferindo um sistema de avaliação baseado no mérito científico ou técnico.

Noutro estudo, Cotgrove e Box (1970) propõem uma categorização de identidades científicas, a partir da importância que o indivíduo confere a cada uma das normas da ciência - universalismo, cepticismo organizado, desinteresse e comunalismo. Com base nas diferentes combinações de normas, estes autores sugerem uma tipologia segundo a qual os cientistas públicos apresentam uma orientação para a comunidade, isto é, valorizam sobretudo a partilha do conhecimento com a comunidade de pares e a pertença à comunidade científica, de que resulta um forte empenhamento na ciência e o reconhecimento da importância da autonomia e da publicação. Por sua vez, os cientistas privados não atribuem a mesma importância a uma estreita ligação à comunidade, o que resulta um menor empenhamento na publicação e no reconhecimento da comunidade científica. Em contrapartida, os privados valorizam sobretudo o reconhecimento dos colegas mais próximos, empenhando-se no estudo de problemas que lhes despertam curiosidade e que representam um desafio e de cuja resolução retiram particular satisfação. A possibilidade de trabalhar no estudo de problemas científicos que lhes interessam pressupõe um elevado nível de autonomia, bastante valorizada pelos cientistas privados, tal como acontecia com os públicos. Em termos de orientação de carreira, os cientistas públicos manifestam maior propensão para uma carreira na universidade, onde encontram as condições de trabalho que melhor vão ao encontro das suas motivações. Os cientistas privados dividem-se entre a preferência pela garantia de uma elevada autonomia científica que encontram na carreira académica e as condições de trabalho e as oportunidades que lhes permitem aplicar o seu conhecimento à resolução de problemas concretos, que encontram na investigação industrial.

A orientação organizacional foi detectada por Kornhauser (1962) sobretudo em indivíduos que valorizam a perspectiva de promoção dentro da organização, uma maior interacção social na sua actividade e a possibilidade de pertencerem a uma empresa tecnologicamente reputada no mercado. Para Cotgrove e Box (1970), os cientistas organizacionais têm uma relação puramente instrumental com a ciência. Por outras palavras, a posição de cientista que ocupam numa dada 
organização é simplesmente o meio de que dispõem para alcançar as posições de topo a que ambicionam. Estes indivíduos são atraídos pela perspectiva de uma carreira compensadora, correspondendo o envolvimento na ciência apenas a uma fase transitória. Valorizam sobretudo as recompensas extrínsecas, como salários elevados e estatuto elevado. Os cientistas organizacionais preferem claramente um emprego na indústria, já que ali encontram melhores perspectivas de ascensão a posições de topo e de compensações salariais mais elevadas. A orientação burocrática foi detectada por Miller e Wager (1971) como estando associada à perspectiva de um progressivo envolvimento em actividades de gestão, valorizando um sistema de avaliação baseado nas competências de gestão e na contribuição do seu trabalho para os resultados económicos da empresa.

Estudos mais recentes têm sugerido outras orientações, para além das tradicionais orientações para a profissão/ciência e organização/gestão. Allen e Katz $(1986,1995)$, por exemplo, sugerem uma terceira orientação - a orientação para projectos - a partir da constatação de que uma percentagem considerável de cientistas e engenheiros se sente mais atraída pela possibilidade de desenvolver projectos interessantes, do que pela perspectiva de progressão de carreira na organização. Por sua vez, Garden (1990) identificou uma quarta orientação - a orientação empreendedora - traduzida na vontade de lançar a sua própria empresa. Esta orientação, que partilha algumas características da orientação para a gestão, para a $\mathrm{C} \& \mathrm{~T}$ e para projectos, foi identificada em indivíduos que não valorizavam a segurança no emprego, preferindo uma actividade que lhes permita elevada autonomia estratégica e operacional, criatividade e liberdade de horário. Nos últimos anos, alguns autores têm vindo a contestar a importância atribuída às orientações técnica e de gestão, sugerindo que outras orientações estilo de vida, localização geográfica, segurança no emprego - possam corresponder melhor às efectivas aspirações de carreira de profissionais de C\&T (Igbarria, Kassicieh e Silver, 1999). Estes autores verificaram que a tendência observada para o incremento da orientação para o estilo de vida se devia, sobretudo, ao crescente número de mulheres entre os profissionais de C\&T.

\section{Metodologia}

Como atrás se referiu, o estudo da integração de doutorados nas organizações de tipo empresarial foi realizado na dupla perspectiva dos indivíduos e das organizações, embora apenas o primeiro nível de análise seja referido neste artigo. A recolha de dados assentou fundamentalmente na realização de um inquérito, sendo a compreensão das atitudes e comportamentos consideravelmente 
enriquecida com a posterior realização de um conjunto de entrevistas que permitiram explorar com maior profundidade algumas das questões identificadas na fase de inquérito. O questionário foi desenvolvido a partir da revisão da literatura e da análise de um conjunto de entrevistas exploratórias. Apesar das conhecidas limitações do questionário enquanto instrumento que permita compreender em profundidade as determinantes e as implicações dos problemas objecto deste estudo, a reduzida informação disponível sobre a população alvo recomenda a abordagem mais transversal que aqui foi adoptada. $\mathrm{O}$ inquérito postal foi realizado utilizando uma amostra constituída por indivíduos que concluíram ou estão em processo de finalização do seu doutoramento, tendo se beneficiado de uma bolsa de diversos programas promovidos pelas entidades portuguesas que financiam a formação avançada de recursos humanos. O total de doutorados e doutorandos inquiridos foi de 2.575 indivíduos, sendo de 2.342 o total de respondentes elegíveis. Foram recebidas 1.062 respostas completas, o que perfaz uma taxa de resposta de $45,3 \%$.

A revisão da literatura efectuada permitiu confirmar a existência de um número muito limitado de estudos empíricos, em formato académico, especificamente dirigidos para a investigação da integração de doutorados nas empresas, bem como de medidas de atracção por diversas actividades, e de atitudes relativamente a diversos aspectos da vida nas empresas, nas universidades e nas instituições de investigação. Neste contexto, e embora utilizando algumas escalas disponíveis na literatura, o instrumento foi, na sua quase totalidade, desenvolvido a partir da literatura e das entrevistas exploratórias realizadas com doutorados e com gestores. Os questionários foram ainda sujeitos a um teste-piloto com uma pequena amostra de respondentes.

\section{Receptividade a uma Carreira no Sector Empresarial}

Relativamente à possibilidade de vir a exercer (ou continuar a exercer, no caso de já o fazer) a sua actividade profissional nas três organizações-tipo (sector universitário, institutos de investigação e sector empresarial), os respondentes mostraram, à partida, receptividade a qualquer uma das opções apresentadas, confirmando que não existe uma rejeição, de princípio, a qualquer uma daquelas saídas profissionais. Como se esperaria, a universidade, enquanto organização empregadora, encontra uma enorme receptividade entre os respondentes. $87 \%$ afirma claramente que encararia bem essa carreira e só $2 \%$ a rejeita. A receptividade a uma carreira no sector empresarial pode também considerar-se elevada, dado que $62 \%$ estão receptivos a essa possibilidade e só $5 \%$ a rejeita. Uma car- 
reira nos institutos de investigação recolhe apenas $56 \%$ de preferências claras, um valor que é possivelmente revelador de alguma indefinição que tem prevalecido em Portugal, quanto ao papel destas instituições.

A receptividade a uma carreira na universidade ou no sector empresarial é independente do sexo do respondente, verificando-se apenas uma maior preferência, entre as mulheres, por uma carreira nos institutos de investigação $(\mathrm{r}=0,15$, $\mathrm{p}<0,01)$. Por outro lado, a análise das respostas obtidas mostra existir uma relação estatisticamente significativa entre a receptividade às várias carreiras e a área científica do doutoramento. A carreira universitária é mais atractiva para os provenientes da área das ciências naturais $(\mathrm{r}=0,10, \mathrm{p}<0,01)$, recolhendo menos entusiasmo apenas da parte dos bolseiros provenientes da área das tecnologias $(\mathrm{r}=-0,12, \mathrm{p}<0,01)$. Pelo contrário, a carreira no sector empresarial é mais atractiva para os doutorados da área das tecnologias $(\mathrm{r}=0,10, \mathrm{p}<0,01)$, sendo menos atractiva para os provenientes das ciências naturais.

Uma análise multivariável da receptividade a uma carreira no sector empresarial permite identificar as variáveis com capacidade explanatória dessa receptividade e, deste modo, compreender melhor o que realmente determina, na perspectiva do indivíduo, a sua atracção por uma carreira nas empresas. A Tabela 1 apresenta um quadro resumido do modelo de regressão múltipla.

Tabela 1: Receptividade a uma Carreira no Sector Empresarial: Análise Multivariável

\begin{tabular}{|l|c|c|c|}
\hline & $\mathrm{R}$ & $\mathrm{R}^{2}$ & $\mathrm{R}^{2}$ ajustado \\
\hline 1. "Sou demasiado académico [...]" & $-0,486$ & 0,236 & 0,235 \\
\hline 2. Receptividade a desenvolver I\&D industrial & 0,530 & 0,281 & 0,280 \\
\hline 3. Orientação empresarial & 0,558 & 0,311 & 0,308 \\
\hline 4. "Não [...] a trabalhar às ordens de um patrão" & $-0,565$ & 0,319 & 0,316 \\
\hline 5. Receptividade a desempenhar act. de gestão & 0,572 & 0,327 & 0,323 \\
\hline $\begin{array}{l}\text { 6. Receptividade a desempenhar act. ligadas à } \\
\text { produção }\end{array}$ & 0,577 & 0,333 & 0,328 \\
\hline
\end{tabular}

A rejeição da ideia "sou demasiado académico para trabalhar em empresas" é identificada pelo modelo como a variável com maior poder explanatório. São igualmente incluídas no modelo a receptividade a desempenhar actividades de I\&D industrial, actividades de gestão e as ligadas à produção, a sua orientação empresarial e a sua rejeição da afirmação "não estou disposto a trabalhar às 
ordens de um patrão". No seu conjunto, estas seis variáveis conseguem explicar quase $33 \%$ da variância da variável receptividade a uma carreira no sector empresarial. Verifica-se, assim, que na perspectiva dos indivíduos a receptividade à ideia de vir a integrar uma empresa e prosseguir a sua carreira no sector privado depende sobretudo de duas ordens de razões. Em primeiro lugar, da forma como o indivíduo se posiciona em relação aos mundos académico e empresarial, a sua postura enquanto académico, a sua atitude em relação às empresas e ao modo de se relacionar com elas, e da sua orientação empresarial. Em segundo lugar, da sua receptividade ao desempenho de actividades mais tipicamente empresariais, como I\&D industrial, gestão e actividades ligadas à produção.

Uma análise bivariável permite ainda concluir que a maior receptividade a desempenhar actividades de gestão é encontrada nos homens $(\mathrm{r}=0,13, \mathrm{p}<0,01)$ provenientes das ciências sociais $(\mathrm{r}=0,09, \mathrm{p}<0,05)$ ou das tecnologias $(\mathrm{r}=0,09$, $\mathrm{p}<0,05)$, e com uma orientação empresarial muito forte $(\mathrm{r}=0,59, \mathrm{p}<0,01)$. Quanto maior a atracção por actividades de gestão, menor a orientação científica $(\mathrm{r}=-0,14, \mathrm{p}<0,01)$. De igual modo, quanto maior a receptividade ao desempenho de actividades de natureza comercial, maior a orientação empresarial $(\mathrm{r}=0,36$, $\mathrm{p}<0,01)$ e menores as orientações científica $(\mathrm{r}=-0,10, \mathrm{p}<0,01)$ e de interacção social na comunidade científica $(r=-0,10, p<0,01)$.

Em termos de actividades, é patente na Tabela 2 a grande receptividade ao exercício da actividade docente. $79 \%$ dos respondentes não tem dúvidas em responder afirmativamente e só 3\% rejeita essa possibilidade. Também se confirma a elevada atracção por uma actividade essencialmente de I\&D: 70\% aceitaa e só 4\% rejeita essa possibilidade. As actividades de I\&D na indústria suscitam menos entusiasmo, embora a percentagem de indivíduos receptivos seja ainda apreciácel (45\%). Por seu lado, é patente a rejeição de actividades de natureza comercial. Apenas 4\% dos respondentes parece entusiasmado com essa possibilidade, enquanto $65 \%$ as rejeitam de imediato. De igual modo, também as actividades ligadas à produção não conseguem atrair incondicionalmente mais de 16\% dos respondentes e mesmo as actividades de gestão só recolhem a adesão imediata de $23 \%$ dos respondentes.

As actividades ligadas à produção atraem sobretudo os mais novos $(\mathrm{r}=-0,07$, $\mathrm{p}<0,05)$, provenientes da área das tecnologias $(\mathrm{r}=0,21, \mathrm{p}<0,01)$ e os que ainda não completaram o doutoramento $(\mathrm{r}=-0,12, \mathrm{p}<0,01)$. Estes indivíduos mostram ter uma apreciável orientação empresarial $(\mathrm{r}=0,18, \mathrm{p}<0,01)$. Verifica-se ainda que, quanto maior a atracção por actividades ligadas à produção, menor a orientação social na comunidade científica $(\mathrm{r}=-0,11, \mathrm{p}<0,01)$ e, sobretudo, menor a orientação científica $(\mathrm{r}=-0,20, \mathrm{p}<0,01)$. Possivelmente porque sendo atraídos por actividades ligadas à produção, não sentem o meio universitário como o seu 
meio natural, os indivíduos atraídos pelas actividades ligadas à produção são os mais insatisfeitos com quase todas as facetas de satisfação que foram medidas. Estão insatisfeitos com aquilo que fazem $(\mathrm{r}=-0,07, \mathrm{p}<0,05)$, com o seu emprego $(\mathrm{r}=-0,13, \mathrm{p}<0,01)$, com a sua carreira $(\mathrm{r}=-0,08, \mathrm{p}<0,05)$ e até com o seu estilo de vida $(\mathrm{r}=-0,12, \mathrm{p}<0,01)$.

\section{Tabela 2: Receptividade e Atraç̧ão por Actividades Profissionais}

\begin{tabular}{|l|c|c|c|}
\hline & Sim & Talvez & Não \\
\hline docente & $79 \%$ & $18 \%$ & $3 \%$ \\
\hline de gestão & $23 \%$ & $47 \%$ & $30 \%$ \\
\hline comercial & $4 \%$ & $31 \%$ & $65 \%$ \\
\hline essencialmente de I\&D & $70 \%$ & $26 \%$ & $4 \%$ \\
\hline de produção & $16 \%$ & $54 \%$ & $30 \%$ \\
\hline de I\&D na indústria & $45 \%$ & $43 \%$ & $12 \%$ \\
\hline de interface I\&D/indústria & $52 \%$ & $39 \%$ & $9 \%$ \\
\hline
\end{tabular}

Os indivíduos atraídos por actividades de I\&D na indústria, apresentam algumas semelhanças com o perfil dos que se sentem atraídos por actividades de produção. Neste caso, são também os indivíduos mais novos $(\mathrm{r}=-0,19, \mathrm{p}<0,05)$, provenientes das tecnologias $(\mathrm{r}=0,19, \mathrm{p}<0,01)$ e que ainda não completaram o doutoramento $(\mathrm{r}=-0,13, \mathrm{p}<0,01)$ que mostram maior receptividade a actividades de I\&D industrial. As semelhanças entre os dois perfis estendem-se à própria insatisfação. Também neste caso, os respondentes manifestam insatisfação com o emprego $(r=-0,18, p<0,01)$, com a carreira $(r=-0,17, p<0,01)$ e com o estilo de vida $(\mathrm{r}=-0,07, \mathrm{p}<0,05)$. A receptividade a actividades de I\&D industrial é tanto maior quanto maior a orientação empresarial $(r=0,16, p<0,01)$ e menor a orientação científica $(r=-0,29, p<0,01)$. Estes resultados mostram ainda que nos doutorados que se sentem atraídos por uma carreira industrial ligada à C\&T, é mais forte a componente empresarial do que a científica. Isto é, trata-se de indivíduos que se sentem atraídos pela vida empresarial, embora, dada a sua formação, pretendam manter uma ligação à C\&T, e não de indivíduos que, sentindo-se cientistas, preferem uma carreira na indústria. 


\section{Orientação Empresarial, Científica e Social}

A análise de componentes principais dos itens que medem as atitudes dos respondentes em relação à carreira, à profissão e à actividade científica permitiu extrair três factores, que se rotularam de orientação científica, empresarial e social na comunidade científica. O primeiro factor extraído, denominado orientação empresarial, revela uma grande atracção por tudo o que diga respeito à actividade empresarial e à actividade de gestão. Este factor é constituído, sobretudo, por itens como "agrada-me a perspectiva de assumir responsabilidades de gestão", "acompanho com atenção a informação de carácter económico", "agrada-me a ideia de me envolver cada vez mais em responsabilidades administrativas à medida que progrido na carreira" e "agrada-me a perspectiva de manter um contacto estreito com clientes e fornecedores".

A orientação empresarial é mais forte nos indivíduos mais novos $(\mathrm{r}=-0,08$, $\mathrm{p}<0,05)$, do sexo masculino $(\mathrm{r}=0,10, \mathrm{p}<0,01)$, e que ainda não completaram $\mathrm{o}$ seu doutoramento $(r=0,09, \mathrm{p}<0,01)$. Ela é igualmente mais forte nos indivíduos provenientes das tecnologias $(\mathrm{r}=0,09, \mathrm{p}<0,01)$, mas, sobretudo, que não sejam provenientes das ciências naturais $(r=-0,12, p<0,01)$. Esta orientação é igualmente mais forte quando os bolseiros não desenvolvem uma actividade profissional enquanto realizam os seus estudos pós-graduados $(\mathrm{r}=-0,07, \mathrm{p}<0,05)$, e quando a investigação realizada não é conduzida em projecto aplicado à organização empregadora $(\mathrm{r}=-0,09, \mathrm{p}<0,05)$. Estes resultados podem, à primeira vista, parecer surpreendentes. Todavia, atendendo a que na grande maioria dos casos a organização empregadora é a universidade, torna-se compreensível que os indivíduos mais orientados para as empresas tenham menor ligação com as organizações empregadoras. Indivíduos com uma forte orientação empresarial são particularmente receptivos a uma carreira no sector empresarial privado $(\mathrm{r}=0,33, \mathrm{p}<0,01)$. Sentem uma atracção muito forte pelo desempenho de actividades de gestão $(r=0,59, p<0,01)$, de natureza comercial $(r=0,36, p<0,01)$, e de produção $(\mathrm{r}=0,18, \mathrm{p}<0,01)$, mas também de I\&D industrial $(\mathrm{r}=0,16, \mathrm{p}<0,01)$ e de interface $(r=0,19, p<0,01)$. Rejeitam a possibilidade de exercer uma actividade profissional num instituto de investigação $(\mathrm{r}=-0,09, \mathrm{p}<0,01)$ e de desempenhar actividades essencialmente de $\operatorname{I} \& \mathrm{D}(\mathrm{r}=-0,18, \mathrm{p}<0,01)$.

Um segundo factor, que se poderia denominar orientação científica, revela uma atracção pela actividade científica, sobretudo de investigação fundamental. Este factor é constituído, sobretudo, por itens como "é mais importante que o meu trabalho contribua para alargar o conhecimento científico do que para resolver problemas concretos", "estou mais preocupado com a qualidade dos resultados do que com a sua aplicação", "a rentabilidade económica do meu traba- 
lho não faz parte das minhas preocupações" e "não seria para mim gratificante que os resultados do meu trabalho científico contribuíssem para o desenvolvimento de um novo produto". Um terceiro factor, que se poderia denominar orientação social, revela grande atracção pela interacção social no seio da equipa e da comunidade científica e, em geral, pelas actividades interactivas associadas ao trabalho do cientista, mas poderia igualmente designar-se por orientação para a equipa e para o networking científico. Este factor é constituído, sobretudo, por itens como "acho muito importante poder participar em conferências onde possa divulgar o meu trabalho e contactar os colegas da área", "é importante para mim transmitir o meu conhecimento a outras pessoas", "é muito importante para o meu trabalho manter contacto com os meus colegas", "aceito trabalhar em projectos de investigação cujos objectivos estejam pré-definidos" e "agrada-me coordenar o trabalho de uma equipa de colaboradores".

\section{Discussão e Conclusóes}

Os indivíduos que manifestam maior atracção por uma carreira no sector empresarial são, sobretudo, provenientes das áreas tecnológicas, com identificação académica mais fraca, isto é, que não se vêem a si próprios como marcadamente académicos e rejeitam as actividades científica e docente que lhe estão associadas, preferindo actividades de I\&D industrial (aplicada) e outras actividades ligadas à gestão e à produção; todavia os indivíduos que manifestam receptividade, de princípio, a desempenhar estas actividades constituem uma minoria. Com efeito, apenas $23 \%$ dos respondentes se mostra claramente receptivo a desempenhar actividades de gestão e apenas $4 \%$ se mostra receptivo a desempenhar actividades de natureza comercial. A orientação empresarial é sobretudo explicada pela atracção por actividades de gestão e de natureza comercial, acompanhamento próximo das questões de natureza económica, e gosto pelo contacto estreito com fornecedores e clientes, encontrando-se principalmente entre indivíduos do sexo masculino. Trata-se de indivíduos para quem as actividades de I\&D são sobretudo instrumentais, não um fim em si mesmas. Ou seja, os indivíduos que manifestam maior receptividade à perspectiva de uma carreira no sector empresarial gostariam de manter algum contacto com as actividades de I\&D, desde que elas fossem desenvolvidas com aplicações em vista, mas rejeitam a possibilidade de uma carreira exclusivamente dedicada à actividade científica. Distinguem-se, neste ponto, dos indivíduos orientados academicamente, que valorizam a investigação realizada, não sendo para eles relevante quais as potenciais aplicações que a sua investigação possa ter. Apesar do carácter instrumental da I\&D para os indivíduos com elevada orientação empresarial, é significati- 
vo que não aceitem abandonar a actividade de $I \& D$, desejando realizá-la a tempo parcial e com alguma forma de ligação externa a instituições do tipo universitário ou de investigação.

Embora não seja muito elevado o número de pós-graduados que se afirma demasiado académico para trabalhar em empresas, quando a questão é colocada em abstracto, o sentido da resposta altera-se consideravelmente, quando a questão se refere ao que acreditam ser a perspectiva das empresas portuguesas sobre o recrutamento de pós-graduados. Neste caso, encontra-se bastante disseminada a ideia segundo a qual eles são percebidos como sobrequalificados pelas empresas portuguesas, uma vez que "as empresas, em Portugal, procuram vendedores e gestores". Como referiu um dos entrevistados, "quando uma empresa contrata um pós-graduado com a finalidade de fazer algum tipo de investigação, acaba por pretender que seja um faz-tudo. Ele deverá coordenar (ou até levar a cabo sozinho) uma determinada actividade de investigação, supervisionar a produção e actuar, simultaneamente, como gestor e relações públicas. O acréscimo de responsabilidades de gestão e administrativas é frequentemente incompatível com a coordenação eficiente de um projecto de investigação". Assim, é frequente encontrar quem argumente que "as empresas não estão genuinamente interessadas em recrutar cientistas" e que "as empresas não apostam na investigação. A investigação raramente produz resultados a curto prazo, pelo que é muitas vezes desprezada."

O desinteresse pelas actividades de I\&D, que percebem existir nas empresas portuguesas, leva estes indivíduos a apontar a sua sobrequalificação como o maior obstáculo a uma eventual integração nas empresas. Um comentário frequentemente ouvido refere que "a actividade empresarial não valoriza tal especialização, e inclusivamente, em algumas situações, tal especialização pode representar uma desvantagem, por considerarem o candidato demasiado qualificado ou até demasiado académico". Por outro lado, a integração nas empresas requer, da parte dos pós-graduados, maior flexibilidade e adaptabilidade, condições indispensáveis a qualquer posto de trabalho, mas particularmente pertinentes no caso das empresas. Alguns entrevistados reconhecem que "muitos doutorados parecem pensar que, pelo facto de terem obtido um dado nível de qualificação, devem ter acesso a uma posição e a um salário de destaque, independentemente de darem provas prévias da sua competência e capacidades. Nada de mais desadequado da realidade do mercado empresarial".

Em suma, este estudo permitiu constatar a existência de uma apreciável disparidade entre a oferta de doutorados e a procura, por parte das organizações de tipo empresarial, de indivíduos com este nível de qualificação; todavia seria incorrecto caracterizar a situação como um caso de excesso de oferta. Verifica- 
se, antes de mais, um desajustamento entre o tipo de formação dada ao nível da pós-graduação e as necessidades das empresas. A longa exposição a práticas e valores académicos cria óbvias dificuldades de adaptação a métodos de trabalho e culturas empresariais, sendo inevitável o choque quando, já doutorados, caem no real para que não estão preparados nem sensibilizados. Para ultrapassar este problema, é necessário repensar os programas de doutoramento, articulando-os com o tecido empresarial, e criando condições para um gradual envolvimento e integração dos pós-graduados no mercado de trabalho.

\section{Agradecimento}

Este projecto foi financiado pela Fundação para a Ciência e a Tecnologia (projecto PCSH/OGE/ 1023/95).

\section{REFERÊNCIAS BIBLIOGRÁFICAS}

ALLEN, T. J.

Distinguishing engineers from scientists. In: KATZ, R. (Ed.). Managing professionals in innovative organizations. Boston: Ballinger, 1988.

ALLEN, T. J.;

KATZ, R.

The dual ladder: motivational solution or managerial delusion?

R\&D Management, v. 16, n. 2, p. 185-197, 1986.

Age, education and the technical ladder. IEEE Transactions on
Engineering Management, v. 39, n. 3, p. 237-245, 1992.

The project-oriented engineer: a dilemma for human resource $\mathrm{m}$ a $\mathrm{n}$ a $\mathrm{g}$ e $\mathrm{m}$ e $\mathrm{n} \mathrm{t}$. $\mathbf{R} \boldsymbol{\&} \mathbf{D}$ Management, v. 25, n. 2, p. 129140, 1995.

ARYEE, S.;

LEONG, C. C.

Career orientations and work outcomes among industrial R\&D professionals. Group and Organization Studies, v. 16, n. 2, p. 193-205, 1991. 
BRETZ, R. D.;

ASH, R. A.;

DREHER, G. F.

Do people make the place? An examination of the attractionselection-attrition hypothesis. Personnel Psychology, v. 42, n. 3, p. 561-581, 1989.

CABLE, D. M.;

JUDGE, T. A.

Pay preferences and job search decisions: a person-organization fit perspective. Personnel Psychology, v. 47, n. 2, p. $317-$ 348, 1994.

CARAÇA, J.

Do saber ao fazer: por que organizar a ciência. Lisboa: Gradiva, 1993.

CHATMAN, J. A.

Matching people and organizations: selection and socialization in public accounting firms. Administrative Science Quarterly, v. 36, n. 3, p. 459484, 1991.

COTGROVE, S.;

BOX, S.

Science, industry and society: studies in the sociology of science. London: Allen \& Unwin, 1970.
DEBACKERE, K.;

CLARYSSE, B.;

RAPPA, M. A.

Autonomy in the industrial laboratory: the dilemma revisited.

The Journal of High Technology Management Research, v. 7, n. 1, p. 61-78, 1996.

DUBINSKAS, F. A.

The cultural chasm: scientists and managers in genetic-engineering firms. Technology Review, p. 24-30, May/ June 1985.

FEIST, G. J.

Personality and working style predictors of integrative complexity: a study of scientists' thinking about research and teaching. Journal of Personality and Social Psychology, v. 67, n. 3, p. 474-484, 1994.

GAGO, J. M.

Manifesto para a ciência em Portugal. Lisboa: Gradiva, 1990.

GARDEN, A. M.

Career orientations of software developers in a sample of high tech companies. R\&D Management, v. 20, n. 4, p. 337352, 1990. 
HOLLAND, J. L.

Making vocational choices. 2. ed. Odessa: Psychological Assessment Resources, 1992.

IGBARRIA, M.;

GREENHAUS, J. H.;

PARASURAMAN, S.

Career orientations of MIS employees: an empirical analysis. MIS Quarterly, v. 15, n. 2, p. 151-169, 1991.

IGBARRIA, M.;

KASSICIEH, S. K.;

SILVER, M.

Career orientations and career success among research, and development and engineering professionals. Journal of Engineering and Technology Management, v. 16, n. 1, p. 2954, 1999.

\section{JACKSON, D. N.}

Scientific and technological innovation: its personological and motivational context. In: JACKSON, D. N.; RUSHTON, J. P. (Eds.). Scientific excellence: origins and assessment. London: Sage Publications, 1987. p.149164.

\section{JONES, O.}

Postgraduate scientists and R\&D: the role of reputation in organizational choice. $\mathbf{R} \boldsymbol{\&} \mathbf{D}$
Management, v. 22, n. 4, p. 349358, 1992.

Human resources, scientists, and internal reputation: the role of climate and job satisfaction. Human Relations, v. 49, n. 3, p. 269-294, 1996.

JUDGE, T. A.;

BRETZ, R. D.

Effects of work values on job choice decisions. Journal of Applied Psychology, v. 77, n. 3, p. 261-271, 1992.

KERR, S.;

VON GLINOW, M. A.;

SCHRIESHEIM, J.

Issues in the study of professionals in organizations: the case of scientists and engineers. Organizational Behavior and Human Performance, v. 18, p. 329-345, 1977.

KORNHAUSER, W.

Scientists in industry: conflict and accomodation. Los Angeles : University of California Press, 1962.

KUNDA, G.

Engineering culture: control and commitment in a high-tech corporation. Philadelphia: Temple University Press, 1992. 
LANCASTER, S. J. et al.

Job applicant similarity on cognitive ability, vocational interests, and personality characteristics: do similar persons choose similar jobs? Educational and Psychological Measurement, v. 54, n. 2, p. 299316, 1994.

MCMILLAN, G. S.;

DEEDS, D. L.

The role of reputation in the recruitment of scientists. R\&D Management, v. 28, n. 4, p. 299304, 1998.

MEGLINO, B. M.;

RAVLIN, E. C.

Individual values in organizations: concepts, controversies and research. Journal of Management, v. 24, n. 3, p. 351390, 1998.

MILLER, G. A.;

WAGER, L. W.

Adult socialization, organizational structure, and role orientation. Administrative Science Quarterly, v. 16, n. 2, p. 151163, 1971.

OCT.

Livro branco do desenvolvimento científico e tecnológico português (1999-2006). [online] Disponível na Internet via WWW.URL : http://
www.mct.pt/Livro-BrancoCT/ 6.htm. 1999.

O'REILLY, C. A.;

CHATMAN, J. A.;

CALDWELL, D. F.

People and organizational culture: a profile comparison to assessing person-fit. Academy of Management Journal, v. 34, n. 3, p. 487-516, 1991.

PELZ, D.;

ANDREWS, F.

Scientists in organizations: productive climates for R\&D. upd. ed. Ann Arbor: Institute for Social Research/ The University of Michigan, 1976.

POSNER, H. Z.

Person-organization values congruence: no support for individual differences as a moderating influence. Human Relations, v. 45, n. 4, p. 351-361, 1992.

RUSHTON, J. P.;

MURRAY, H. G.;

PAUNONEN, S. V.

Personality characteristics associated with high research productivity. In: JACKSON, D. N.; RUSHTON, J. P. (Eds.). Scientific excellence: origins and assessment. London: Sage Publications, 1987. p. 129-148. 
SAMSOM, K. J.;

GURDON, M. A.

University scientists as entrepreneurs: a special case of technology transfer and high-tech venturing. Technovation, v. 13, n. 2, p. 63-71, 1993.

SCHEIN, E. H.

The individual, the organization, and the career: a conceptual scheme. Journal of Appllied Behavioral Science, v. 7, n. 4, p. 401-426, 1971.

How career anchors hold executives to their career paths. Personnel, v. 52, n. 3, p. 11-24, 1975.

SCHNEIDER, B.;

GOLDSTEIN, H. W.;

SMITH, D. B.

The ASA framework: an update.

Personnel Psychology, v. 48, n. 4, p. 747-773, 1995.
SCOTT, N. A.;

SEDLACEK, W. E.

Personality differentiation and prediction of persistence in physical science and engineering. Journal of Vocational Behavior, v. 6, p. 205-216, 1975.

SEIXAS, P. C.

Portuguese doctoral studies: between career and education. European Journal of Education, v. 33, n. 2, p. 205215, 1998.

SHAPIRA, Z.;

GRIFFITH, T. L.

Comparing the work values of engineers with managers, production, and clerical workers: a multivariate analysis. Journal of Organizational Behavior, v. 11, n. 4, p. 281-292, 1990.

TURBAN, D. B.;

KEON, T. L.

Organizational attractiveness: an interactionist perspective. Journal of Applied Psychology, v. 78, n. 2, p. 184-193, 1993. 